Methods: We retrospectively recorded clinical and laboratory parameters in patients admitted to our ICU from 2000-2018. We performed risk factor analysis using univariate and multivariate logistic regression. In the multivariate case we applied the least absolute shrinkage and selection operator (lasso) method for variable selection. We considered average marginal effects and partial dependence plots in order to describe the influence of various independent variables on the probability of death more specifically. We evaluated our new score by comparing the corresponding area under the curve (AUC) to the AUC corresponding to the established SAPS2 score.

Results: We analyzed 58 patients with AAV (39 granulomatosis with polyangiitis, 19 with microscopic polyangiitis) with a mean age of $74 \pm 14$ (GPA) and $73 \pm 12$ (MPA). $19 / 39$ (48.7\%) of GPA and 9/19 (47.4\%) were female. Reasons for admission included disease manifestations or infectious complications from treatment (e. g. pneumonia, urinary tract infection). In total, 13/58 (22.4\%) patients died throughout the study (10 GPA, 3 MPA patients). Using a cut-off threshold of 40 for SAPS2, sensitivity and specificity for mortality were 0.92 and 0.60 , respectively. Confidence interval for the AUC was $[0.68,0.95]$. In the fitted multivariate logistic regression model, lasso was applied for variable selection. The identified variables included: disease duration, $\mathrm{pH}$, procalcitonin, hemoglobin, leukocytes on admission, coronary heart disease, and pneumonia on admission. The estimated mortality is given by the formula $f(\beta 0+\beta 1 \chi 1+\ldots+\beta 7 \chi 7)$, where $f(u)=1 /(1+\exp (-u))$. Table 1 shows the estimated mortality for various values of the new score.

Table 1. Example scores predicting mortality using the novel formula.

\begin{tabular}{lc}
\hline Score & Predicted mortality \\
\hline-2.2 & 0.1 \\
-1.1 & 0.25 \\
0 & 0.5 \\
1.1 & 0.75 \\
2.2 & 0.9
\end{tabular}

Testing if the AUC corresponding to the new model is significantly larger than the one corresponding to the SAPS2 score as independent variable resulted in $p$-value of 0.037 . To identify possible overfitting, a 5 -fold cross validation was performed. This resulted in a $\mathrm{Cl}$ for the AUC of $[0.64,0.96]$, suggesting that the new score allows for simpler prediction of mortality.

Conclusion: We developed a novel formula corresponding to a score which is able to simpler predict mortality in patients with AAV admitted to the ICU. We will test our formula in the available ICU database MIMIC III, which comprises a large dataset of ICU patients.

REFERENCES:

[1] Kitching AR, Anders H-J, Basu N, Brouwer E, Gordon J, Jayne DR, et al. ANCA-associated vasculitis. Nature Reviews Disease Primers. 2020 Aug 27;6(1):1-27.

[2] Le Gall JR, Lemeshow S, Saulnier F. A new Simplified Acute Physiology Score (SAPS II) based on a European/North American multicenter study. JAMA. 1993 Dec 22;270(24):2957-63.

Disclosure of Interests: PETER KORSTEN Speakers bureau: Chugai, Boehringer-Ingelheim, Sanofi Aventis, Abbvie, GSK, Novartis, Consultant of: Lilly, Gilead, Abbvie, Boehringer-Ingelheim, GSK, Novartis, Grant/research support from: GSK, Fabian Kück: None declared, Karaine Tejiozem Donfack: None declared, Radovan Vasko: None declared, Andreas Lena: None declared, Björn Tampe: None declared

DOI: 10.1136/annrheumdis-2021-eular.1209

\begin{tabular}{|l|l}
\hline POS0826 SKIN LIMITED IGA VASCULITIS IN ADULTS \\
\hline
\end{tabular}

A. Hočevar ${ }^{1,2}$, J. Ostrovrsnik ${ }^{1}$, K. Perdan-Pirkmajer ${ }^{1}$, M. Tomsic ${ }^{1,2}$, Z. Rotar ${ }^{1,2}$. ${ }^{1}$ University Medical Centre Ljubljana, Department of Rheumatology, Ljubljana, Slovenia; ${ }^{2}$ Medical Faculty, University of Ljubljana, Internal Medicine, Ljubljana, Slovenia

Background: IgA vasculitis (IgAV) could be limited to skin or evolve into a systemic disease, affecting characteristically joints, gastrointestinal tract and/or kidneys.

Objectives: We aimed to look for differences between adult IgAV patients with disease limited to skin compared to systemic IgAV.

Methods: Medical records of histologically proven adult IgAV cases, diagnosed between January 2010 and December 2020 at our secondary/tertiary rheumatology centre were analyzed.

Results: During the 132-month observation period we identified 328 new IgAV cases $(59.5 \%$ males, median (IQR) age $64.3(45.1 ; 76.1)$ years). Ninety-four $(40.2 \%)$ patients had skin limited disease, and the rest systemic IgAV.
Clinical differences between skin limited and systemic adult IgAV are presented in table 1. Adults with IgAV limited to skin were significantly older had less commonly skin lesions above the waistline and a lower level of $C$ reactive protein compared to patients with a systemic disease. There were no differences in the frequency of skin necroses between the compared IgAV subgroups. The frequency of potential vasculitis triggers (prior infections, new medications, malignancy) was similar between the compared subgroups.

Table 1. Clinical characteristics of IgA vasculitis patients with skin limited and systemic disease

\begin{tabular}{lccc}
\hline Clinical characteristics & Skin limited IgAV (94) & Systemic IgAV (234) & P value \\
\hline Male gender (\%) & 54.3 & 61.5 & 0.263 \\
Age (years) & $68.0(55.0-80.5)$ & $61.5(41.7-75.8)$ & 0.007 \\
Current smoker (\%) & 13.8 & 21.8 & 0.123 \\
Antecedent infection (\%) & 28.7 & 33.8 & 0.434 \\
New medication & 23.4 & 23.5 & 1.0 \\
History of cancer & 12.8 & 10.7 & 0.569 \\
Symptom duration (days) & $7(5-21)$ & $8(5-14)$ & 0.756 \\
Purpura above waistline & 36.2 & 55.6 & 0.002 \\
Skin necroses $(\%)$ & 52.1 & 45.7 & 0.329 \\
ESR $/ \mathrm{mm} / \mathrm{h}$ ) ${ }^{*}$ & $32(18-52)$ & $34(17-53)$ & 0.873 \\
CRP $(\mathrm{g} / \mathrm{l}$ * & $13.5(1-32)$ & $30(11-68)$ & $<0.001$ \\
Elevated serum IgA (\%) & 50.6 & 49.1 & 0.892 \\
\hline
\end{tabular}

Legend: * median and IQR;

Follow up data were available for $250(76.2 \%)$ patients. During the follow up of median (IQR) 12.5 (6.8 - 22.4) months 35 patients relapsed (13/70 $(18.6 \%)$ with skin limited IgAV and $22 / 180$ (12.2\%) with systemic IgAV, $\mathrm{p}=0.224)$.

Conclusion: Skin limited IgAV was associated with older age and less extensive skin puprura in adults. However, relapses of purpura were as common as in systemic IgAV.

Disclosure of Interests: None declared

DOI: 10.1136/annrheumdis-2021-eular.1383

\section{POS0827 1 HEPATOTROPIC VIRUSES WITH HIGHER RHEUMATOID FACTOR, BUT NOT RHEUMATIC DISEASES LINK TO PREVALENT CRYOGLOBULINEMIA. CORRELATION OF CLINICAL AND SEROLOGICAL MARKERS WITH ETIOLOGICAL CAUSES}

S. Jeria Navarro ${ }^{1}$, T. Franco ${ }^{2}$, L. Alserawan ${ }^{2}$, D. Lobo Prat ${ }^{1}$, A. García-Guillén ${ }^{1}$, L. Sainz Comas ${ }^{1}$, H. Park ${ }^{1}$, A. M. Millán Arciniegas ${ }^{1}$, P. Moya ${ }^{1}$, B. Magallares ${ }^{1}$, C. Díaz-Torné ${ }^{1}$, E. Moga ${ }^{2}$, C. Juarez ${ }^{2}, \mathrm{H}$. Corominas ${ }^{1} .{ }^{1}$ Hospital Universitari de la Santa Creu i Sant Pau \& Dos de Maig, Rheumatology Unit, Barcelona, Spain

${ }^{2}$ Hospital Universitari de la Santa Creu i Sant Pau, Immunology Unit, Barcelona, Spain

Background: Cryoglobulinemia (CG) is a rare phenomenon, which is defined as the persistent presence in serum of abnormal immunoglobulins (Igs) that precipitate in vitro at less than $37^{\circ} \mathrm{C}$ and dissolve when the temperature rises again. Is related to hematological disorders, infections and autoimmunes diseases.

Objectives: To describe the differential clinical features, serological and demographics in a cohort of patients diagnosed with CG.

Methods: We describe a retrospective cohort of 252 cryoglobulin $(\mathrm{Cg})$ positive samples, obtained from a database from the immunology laboratory of a tertiary hospital (November 2018-November 2019). We obtained 182 patients with $C G$, classified according to their etiology into 4 groups: 1)Rheumatic diseases (RD) that includes rheumatoid arthritis, Systemic lupus erythematosus, Sjögren's syndrome and Systemic scleroderma, 2)Hepatotropic viruses (HV) with patients diagnosed with Hepatitis C virus, B virus and both, 3)Hematological diseases (HD) and 4)Essential cryoglobulinemia (CGE). Demographic variables, clinical and serological data were collected. A comparative analysis was performed with the Mann-Whitney $U$ test and the multivariate Kruskal-Wallis test, nonparametric variables were compared using a Wilcoxon test. Ten patients, with more than one disease from 4 groups, were excluded from the study.

Results: Out of 182 reviewed patients, 172 were included in the study. Mean age at diagnosis was $59.7( \pm 14.0)$. Demographic, clinical and laboratory characteristics are described in table 1. Mixed CG was the predominant subtype, in $116(67.4 \%)$ patients. The most prevalent CG-associated diseases were HV infection with $91(53 \%)$ patients. CGE mostly presented with cutaneous manifestations ( $p=0.0001)$, particularly purpura. In RD group the presence of Raynaud and non-erosive arthritis $(p=0.0001)$ was relevant. Laboratory findings showed that $C G$ titration varies according to the etiology, being HD the one with the highest values with $292.2( \pm 546.2)$. There is significant difference in 
terms of the average of rheumatoid factor (RF) being higher in the group by CGE. On other hand, the group HV presented more consumption of complement, and showed the lowest average $p=0.0001$, without more severe clinical manifestations.

Table 1.

\begin{tabular}{|c|c|c|c|c|c|}
\hline & $R D(n=47)$ & $\mathrm{HV}(\mathrm{n}=91)$ & HD $(n=17)$ & CGE $(n=17)$ & \\
\hline Gender,n(\%) F & $42(89.4)$ & $57(62.6)$ & $7(41.2)$ & $11(64.7)$ & \\
\hline Age at dg, years, ( $(\mathrm{SD})$ & $60.6( \pm 14)$ & $59.6( \pm 13.1)$ & $61.1( \pm 16.6)$ & $56.3( \pm 20.8)$ & $\mathrm{p}=0.8$ \\
\hline \multicolumn{6}{|c|}{ CLINICAL CHARACTERISTICS } \\
\hline Skin n (\%) & $18(38.3)$ & $10(11.0)$ & $2(11.8)$ & $9(52.9)$ & $\mathrm{p}<0.001$ \\
\hline Raynaud n (\%) & $14(29.8)$ & & $1(5.9)$ & $3(17.6)$ & $p<0.001$ \\
\hline Purpura n (\%) & $6(12.8)$ & $9(9.9)$ & $2(11.8)$ & $6(35.3)$ & $p=0.04$ \\
\hline Acrocyanosis n (\%) & $6(12.8)$ & & & $1(5.9)$ & $p=0.0033$ \\
\hline Ulcers n (\%) & $3(6.4)$ & $2(2.2)$ & - & $2(11.8)$ & $p=0.19$ \\
\hline Peripheric Neuro n (\%) & $10(21.3)$ & $9(9.9)$ & $1(5.9)$ & $4(23.5)$ & $p=0.13$ \\
\hline $\mathrm{N}$-E arthritis $\mathrm{n}(\%)$ & $22(46.8)$ & $8(8.8)$ & $1(5.9)$ & $4(23.5)$ & $\mathrm{p}<0.001$ \\
\hline $\begin{array}{l}\text { GMN n (\%) } \\
\text { LABORATORY }\end{array}$ & $5(10.6)$ & $3(3.3)$ & $1(5.9)$ & $3(17.6)$ & $p=0.11$ \\
\hline $\mathrm{Cg}(\mathrm{mg} / \mathrm{dL}) \bar{x}( \pm \mathrm{SD})$ & $26.7( \pm 63.2)$ & $65.8( \pm 2$ & $\begin{array}{c}292.4 \\
( \pm 546.2)\end{array}$ & 47.59 & t \\
\hline Isotype IgG, n (\%) & $\begin{array}{r}G+M 26 \\
(55.3)\end{array}$ & $\mathrm{G}+\mathrm{M} 72(79.1)$ & M 8 (47.1) & $\begin{array}{r}G+M 12 \\
(70.6)\end{array}$ & \\
\hline$\beta 2 \mathrm{M}(\geq 1.8 \mathrm{mg} / \mathrm{L}), \mathrm{n}(\%)$ & $7 / 40(17.5 \%)$ & $1 / 5(20.0 \%)$ & $3 / 12(25.0 \%)$ & - & $p=0.44$ \\
\hline $\mathrm{RCP}(\mathrm{mg} / \mathrm{L})$ p 50 & $10.3( \pm 26.2)$ & $3.9( \pm 3.0)$ & $13.4( \pm 18.3)$ & $8.5( \pm 12.0)$ & $p=0.47$ \\
\hline ESR $(\mathrm{mm} / \mathrm{h}) \mathrm{p} 50$ & $40.0( \pm 28.5)$ & $20.3( \pm 20.2)$ & $35.4( \pm 35.1)$ & $24.5( \pm 25.0)$ & $\begin{array}{c}p= \\
0.0003\end{array}$ \\
\hline RF + (>20Ul/mL), n (\%) & $19 / 46(41.3)$ & $44 / 86(51.2)$ & $5 / 11(45.5)$ & $7 / 17(41.2)$ & $p=0.09$ \\
\hline p50 & $90.6( \pm 175.9)$ & $161.0( \pm 219.5)$ & $94.8( \pm 135.6)$ & $\begin{array}{l}284.5 \\
( \pm 619.3)\end{array}$ & $\mathrm{p}<0.001$ \\
\hline C3 (<85mg/dL), n \%) & $20(42.6)$ & $47(51.6)$ & $3(17.6)$ & $3(17.6)$ & $p=0.13$ \\
\hline $\bar{x}( \pm S D)$ & $90.1( \pm 28.6)$ & $68.5( \pm 10.8)$ & $99.1( \pm 29.0)$ & $114.8( \pm 12.7)$ & $\mathrm{p}<0.001$ \\
\hline C4 (<12mg/dL), n (\%) & $17(36.2)$ & $36(39.6)$ & - & $3(17.6)$ & $p=0.02$ \\
\hline $\bar{x}( \pm S D)$ & $15.6( \pm 9.0)$ & $7.6( \pm 3.5)$ & $20.4( \pm 7.4)$ & $21.1( \pm 9.5)$ & $p<0.001$ \\
\hline
\end{tabular}

Conclusion: In our cohort, not all patients with CG presented clinical manifestations being those associated with CGE and RD those with the highest skin and joint expression. The most prevalent association of CG continues to be the HV and we confirmed the characteristic decrease in C3 and C4 complement levels, together with the positivity for RF.

Disclosure of Interests: None declared

DOI: 10.1136/annrheumdis-2021-eular.1758

\section{POS0828 $\quad$ CONSISTENT EFFICACY WITH APREMILAST IN MEN AND WOMEN TO TREAT ORAL ULCERS ASSOCIATED WITH BEHCCET'S SYNDROME: PHASE 3 RELIEF STUDY RESULTS}

G. Hatemi ${ }^{1}$, A. Mahr ${ }^{2}$, M. Takeno ${ }^{3}$, D. Kim ${ }^{4}$, M. Melikoglu' ${ }^{1}$, S. Cheng ${ }^{5}$, S. Richter ${ }^{5}$ S. Jardon ${ }^{5}$, M. Paris ${ }^{5}$, M. Chen ${ }^{5}$, Y. Yazici ${ }^{6} .{ }^{1}$ Istanbul University-Cerrahpassa, Cerrahpaşa Medical School and Behçet's Disease Research Center, Division of Rheumatology, Department of Internal Medicine, Istanbul, Turkey; ${ }^{2}$ Cantonal Hospital St. Gallen, Department of Rheumatology, St. Gallen, Switzerland; ${ }^{3}$ Nippon Medical School, Rheumatology, Kawasaki, Japan; ${ }^{4}$ Yonsei University College of Medicine and Severance Hospital, Department of Internal Medicine, Seoul, Korea, Rep. of (South Korea); ${ }^{5}$ Amgen Inc., Global Medical Affairs, Thousand Oaks, United States of America; ${ }^{6}$ New York University School of Medicine, Department of Medicine, New York, United States of America

Background: Painful, recurring oral ulcers (OU) associated with Behçet's syndrome negatively affect quality of life (QoL). Differences across sexes were reported in the frequency of disease manifestations, disease course, and response to colchicine. The phase 3, randomized, double-blind, placebo (PBO)-controlled RELIEF study showed overall efficacy of apremilast (APR) for OU associated with Behçet's syndrome, including improvements in OU pain, disease activity, and QoL.

Objectives: To evaluate the consistency of efficacy with APR in men and women with Behçet's syndrome.

Methods: Adults with active Behcet's syndrome and $\geq 3 \mathrm{OU}$ at randomization or $\geq 2 \mathrm{OU}$ at screening and randomization, without active major organ involvement, were randomized to APR $30 \mathrm{mg}$ BID or PBO during the 12-wk PBO-controlled phase. Randomization was stratified by sex. The primary endpoint was area under the curve for the number of $\mathrm{OU}$ through Wk $12\left(\mathrm{AUC}_{\mathrm{Wk} 0-12}\right)$ to assess continued efficacy over the time period in a symptom that waxed and waned. Key secondary endpoints included OU pain, complete response (OU-free), maintenance of complete response, and QoL at Wk 12. Disease activity was also assessed using Behçet's Syndrome Activity Score (BSAS) and Behçet's Disease
Current Activity Index Form (BDCAF). QoL was assessed using Behçet's Disease QoL (BDQoL). Prespecified subgroup analyses in men and women were performed to assess treatment effect in primary and secondary endpoints.

Results: Eighty men and 127 women were randomized and received $\geq 1$ dose of study medication. Mean age was $38.7 \mathrm{yrs}$ (men) and $40.8 \mathrm{yrs}$ (women). Mean (SD) OU count at baseline was 3.4 (1.4) (PBO) and 3.7 (1.5) (APR) for men and 4.3 (3.2) (PBO) and 4.5 (4.5) (APR) for women. Greater improvements in favor of APR vs PBO were observed in $\mathrm{AUC}_{W \mathrm{~W} 0-12}$ in men and women (Figure 1). Consistency in efficacy with APR was observed between men and women, with greater reduction in pain and achievement of OU complete response (OU-free) and maintenance of response at Wk 12 vs PBO (Table 1). In men and women, consistent treatment effects in favor of APR vs PBO were observed for disease activity and QoL measures, although moderate treatment differences were observed in BDCAI (men/women) and BDQoL (men) (Table 1).

Conclusion: Consistent treatment effects in favor of APR vs PBO in clinically relevant outcomes, including OU number and pain, OU complete response, and disease activity measures, were observed in men and women with $\mathrm{OU}$ associated with Behçet's syndrome.

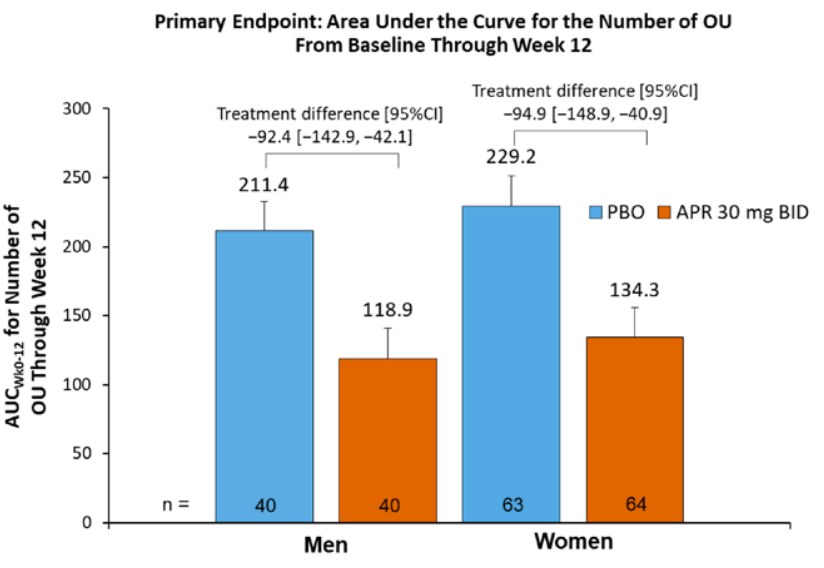

Intent-to-treat population. Error bars represent standard error. Multiple imputation used for imputing missing data.

\begin{tabular}{|c|c|c|c|c|c|c|}
\hline & \multicolumn{6}{|c|}{ Key Secondary Efficacy Outcomes at Wk 12} \\
\hline & \multicolumn{2}{|c|}{ Men } & \multicolumn{4}{|c|}{ Women } \\
\hline & $\begin{array}{c}\text { PBO } \\
(n=40)\end{array}$ & $\begin{array}{c}\text { APR } \\
(n=40)\end{array}$ & $\begin{array}{c}\text { Tx Difference } \\
{[95 \% \mathrm{Cl}]}\end{array}$ & $\begin{array}{c}\text { PBO } \\
(n=63)\end{array}$ & $\begin{array}{c}\text { APR } \\
(n=64)\end{array}$ & $\begin{array}{c}\text { Tx } \\
\text { Difference } \\
{[95 \% \mathrm{Cl}]}\end{array}$ \\
\hline OU CR, n/N (\%) & $\begin{array}{c}8 / 40 \\
(20.0)\end{array}$ & $\begin{array}{l}21 / 40 \\
(52.5)\end{array}$ & $\begin{array}{c}32.6 \\
{[12.8,52.4]}\end{array}$ & $\begin{array}{l}15 / 63 \\
(23.8)\end{array}$ & $\begin{array}{l}34 / 64 \\
(53.1)\end{array}$ & $\begin{array}{c}29.3 \\
{[13.2,45.4]}\end{array}$ \\
\hline $\begin{array}{l}\text { OU CR } 6+6^{*} \\
n / N(\%)\end{array}$ & $\begin{array}{l}1 / 40 \\
(2.5)\end{array}$ & $\begin{array}{l}10 / 40 \\
(25.0)\end{array}$ & $\begin{array}{c}22.8 \\
{[8.8,36.8]}\end{array}$ & $\begin{array}{l}4 / 63 \\
(6.3)\end{array}$ & $\begin{array}{l}21 / 64 \\
(32.8)\end{array}$ & $\begin{array}{c}26.5 \\
{[13.6,39.3]}\end{array}$ \\
\hline Pain (VAS)† & $\begin{array}{l}-12.0 \\
(4.8)\end{array}$ & $\begin{array}{l}-37.6 \\
(4.9)\end{array}$ & $\begin{array}{c}-25.6 \\
{[-37.2,-14.1]}\end{array}$ & $\begin{array}{l}-17.4 \\
(4.4)\end{array}$ & $\begin{array}{l}-41.5 \\
(4.3)\end{array}$ & $\begin{array}{c}-24.1 \\
{[-34.9,-13.3]}\end{array}$ \\
\hline BSAS† & $\begin{array}{l}-1.3 \\
(2.4)\end{array}$ & $\begin{array}{r}-14.4 \\
(2.4)\end{array}$ & $\begin{array}{c}-13.1 \\
{[-18.8,-7.3]}\end{array}$ & $\begin{array}{l}-7.7 \\
(2.4)\end{array}$ & $\begin{array}{l}-19.7 \\
(2.4)\end{array}$ & $\begin{array}{c}-12.0 \\
{[-18.0,-6.0]}\end{array}$ \\
\hline BDCAF† & & & & & & \\
\hline BDCAI & $\begin{array}{l}-0.1 \\
(0.3)\end{array}$ & $\begin{array}{l}-0.5 \\
(0.3)\end{array}$ & $\begin{array}{c}-0.4 \\
{[-1.1,0.4]}\end{array}$ & $\begin{array}{l}-0.7 \\
(0.3)\end{array}$ & $\begin{array}{l}-1.3 \\
(0.3)\end{array}$ & $\begin{array}{c}-0.6 \\
{[-1.2,0.0]}\end{array}$ \\
\hline $\begin{array}{l}\text { Patient's Perception of } \\
\text { Disease Activity }\end{array}$ & $\begin{array}{l}-0.2 \\
(0.3)\end{array}$ & $\begin{array}{l}-1.4 \\
(0.3)\end{array}$ & $\begin{array}{c}-1.2 \\
{[-1.9,-0.5]}\end{array}$ & $\begin{array}{l}-1.0 \\
(0.2)\end{array}$ & $\begin{array}{l}-1.8 \\
(0.2)\end{array}$ & $\begin{array}{c}-0.9 \\
{[-1.4,-0.3]}\end{array}$ \\
\hline $\begin{array}{l}\text { Clinician's Overall } \\
\text { Perception of } \\
\text { Disease Activity }\end{array}$ & $\begin{array}{l}-0.2 \\
(0.3)\end{array}$ & $\begin{array}{l}-1.5 \\
(0.3)\end{array}$ & $\begin{array}{c}-1.3 \\
{[-1.9,-0.7]}\end{array}$ & $\begin{array}{l}-1.0 \\
(0.2)\end{array}$ & $\begin{array}{l}-1.7 \\
(0.2)\end{array}$ & $\begin{array}{c}-0.7 \\
{[-1.3,-0.2]}\end{array}$ \\
\hline BDQoL† & $\begin{array}{l}-0.7 \\
(1.0)\end{array}$ & $\begin{array}{l}-2.2 \\
(1.0)\end{array}$ & $\begin{array}{c}-1.5 \\
{[-3.8,0.8]}\end{array}$ & $\begin{array}{l}-0.3 \\
(0.9)\end{array}$ & $\begin{array}{l}-4.4 \\
(0.9)\end{array}$ & $\begin{array}{c}-4.1 \\
{[-6.3,-2.0]}\end{array}$ \\
\hline
\end{tabular}

LOCF analyses. *Proportion of patients achieving an $\mathrm{OU} \mathrm{CR}$ by $\mathrm{Wk} 6$, and remainin $\mathrm{OU}$-free for $\geq 6$ additional wks during the 12-wk PBO-controlled treatment phase. TLS mean (SE) change from baseline. BSAS = Behçet's Syndrome Activity Scores; BDCAF = Behçet's Disease Activity Form; $\mathrm{CR}=$ complete response; $\mathrm{n}=$ number of patients randomized to treatment; $T x=$ treatment

Acknowledgements: This study was funded by Celgene. Additional analyses were funded by Amgen Inc. Writing support was funded by Amgen Inc. and provided by Kristin Carlin, RPh, MBA, of Peloton Advantage, LLC, an OPEN Health company. 